\title{
Pengaruh Lama Penyimpanan dan Konsentrasi Aplikasi Ekstrak Biji Mahoni Hasil Fermentasi terhadap Efektivitasnya
}

\section{(Effect of Storage Period and Concentration Application of Fermented Mahogany Seed Extract on Its Effectiveness)}

\author{
Hamdani $^{1{ }^{*}}$, Dedi Supriyatdi ${ }^{1)}$ \\ 1) Jurusan Budidaya Tanaman Perkebunan Politeknik Negeri Lampung, Jl. Soekarno-Hatta No. 10 \\ Rajabasa, Bandar Lampung, 35144 \\ E-mail:kajikhamdani@polinela.ac.id
}

\begin{abstract}
Armyworm (Spodoptera litura F.) as a polyfagous insect is a key pest of either food crops or estate crops. The larva often attack leaves of beans, cereal, shallot, cabbage, cotton, tobacco, and sugarcane. Synthetic insecticides are usually used $2-3$ times a week in order to manage this insect. The use of synthetic insecticides need high cost, have negative impacts such as insect resistance and resurgence, killing non-target insects, residual effects on yield, and environmental contamination and pollution. Botanical insecticide has a highly potential to be used in IPM because of its characteristics (no residual effect, cheap, easy to get and easy to apply). Mahogany seeds contain alkaloid, saponin, and flavonoid that have good insecticide activity. Extract of mahogany seeds can be used as insecticide, anti-feedant, growth retardant, and fertile retardant. The effectivity of mahogany seed extracts is affected by storage time and its concentration. The results of the experiment are the extract of mahogany seeds can be stored up to 3 weeks, and the highest effective is reached by the concentration of $20 \%$, followed by $10 \%-15 \%$ concentration as moderately effective.
\end{abstract}

Keywords: botanical insecticides, extract, mahogany seed

Diterima: 5 Januari 2017 / Disetujui: 10 April 2017 / Diterbitkan: 15 Mei 2017

\section{PENDAHULUAN}

Ulatgrayak (Spodoptera litura F.) merupakan hama yang penting pada tanaman pangan maupun pada tanaman perkebunan, karena bersifat polifag. Larva hama ini sering menyebabkan kerusakan daun pada tanaman kacang-kacangan, jagung, padi, bawang, slada, sawi, kapas, tembakau, dan tebu (Kalshoven, 1981).

Upaya pengendalian yang dilakukan umumnya menggunakan insektisida sintetik dengan frekuensi penyemprotan terjadwal 2 - 3 kali per minggu. Namun tindakan tersebut tidak mampu menurunkan populasi, karena larva ulatgrayak pada siang hari bersembunyi di dalam tanah. Selain itu pengendalian hama tanaman dengan insektisida sintetik memerlukan biaya tinggi, juga dapat menimbulkan dampak negatif, seperti resistensi dan resurjensi hama, terbunuhnya organisme bukan sasaran termasuk musuh alami, keracunan pada manusia dan ternak, kontaminasi oleh residu bahan beracun pada hasil panen, dan pencemaran lingkungan secara umum. 
Sehubungan dengan hal tersebut penelitian pemanfaatkan ekstrak tanaman untuk mengendalikan populasi dan serangan hama tanaman perlu dilakukan agar diperoleh/diketahui alternatif pengedalian hama yang lebih murah, aman terhadap lingkungan, dan dapat diterima oleh para petani. Dengan demikian ketergantungan petani dengan pestisida sintetik dapat dikurangi bahkan dihilangkan dan kerusakan lingkungan secara umum dapat dihindari, sehingga konsep pertanian ekologis atau pertanian berkelanjutan dapat diwujudkan.

Hingga saat ini telah diketahui terdapat tiga sumber insektisida alami yang penting dan memiliki prospek yang baik untuk dikembangkan, yaitu tumbuhan, mikroorganisme tanah, dan organisme laut. Jenis tumbuhan yang diketahui berpotensi sebagai sumber insektisida nabati antara lain famili Meliaceae, Annonaceae, Piperaceae, Asteraceae, Zingiberaceae dan Leguminosae (Chiu, 1985; Koul et al., 1997; Prijono, 1998).

Tanaman Meliaceae yang potensial antara lain mahoni, mimba, mindi, suren, dan culan (Chiu, 1985; Ewete et al., 1996; Koul et al., 1997). Ekstrak beberapa bagian tanaman tersebut terbukti aktif sebagai insektisida, antifeedant, penghambat perkembangan, serta penghambat peneluran, namun yang paling aktif adalah ekstrak biji (Dadang, 1999; Prijono, 1999).

Biji tanaman mahoni (Swietenia mahagoni (L.) Jack) anggota famili Meliaceae, mengandung unsur kimia alkaloid, saponin dan flavonoida, telah terbukti memiliki aktivitas insektisida yang baik (Ewete et al., 1996; Koul et al., 1997). Ekstrak biji mahoni aktif sebagai insektisida dan regulator pertumbuhan (IGR) terhadap larva ulatgrayak (Hamdani dan Supriyatdi, 2004). Pada penelitian lain, telah diketahui bahwa ekstrak biji mahoni dapat menurunkan populasi hama penghisap buah lada (Dasynus piperis China) (Hamdani dan Supriyatdi, 2005).

Berdasarkan latar belakang tersebut di atas serta mempertimbangkan kesulitan mendapatkan bahan baku di sekitar lahan pertanian, maka penelitian mengenai lama penyimpanan dan konsentrasi aplikasi ekstrak biji mahoni yang diperoleh dengan metode fermentasi untuk mengendalikan Ulatgrayak perlu dilakukan. Penelitian ini bertujuan untuk mengetahui masa penyimpanan ekstrak biji mahoni yang diperoleh dengan metode fermentasi serta toksisitasnya, mengetahui konsentrasi aplikasi ekstrak biji mahoni yang tepat setelah disimpan beberapa waktu untuk mengendalikan ulatgrayak, dan mengetahui apakah terdapat interaksi antara lama penyimpanan dengan konsentrasi aplikasi terhadap toksisitas insektisida nabati ekstrak biji mahoni hasil fermentasi terhadap ulatgrayak.

\section{METODE PENELITIAN}

Penelitian dilaksanakan di Laboratorium Ilmu Tanah, Jurusan Budidaya Tanaman Perkebunan, Politeknik Negeri Lampung, pada bulan September sampai dengan November 2013. Bahan baku insektisida nabati yang diuji adalah biji mahoni (S. mahagoni). Bahan tersebut 
diekstraksi dengan metode fermentasi, dalam hal ini diperlukan bahan-bahan lain seperti molase, bio-aktivator (EM4), dan air.

Serangga uji yang digunakan adalah larva ulatgrayak, instar II dan III yang merupakan hasil perbanyakan di Laboratorium. Imago dipelihara dalam kurungan plastik-kasa dengan bingkai kayu yang berukuran $40 \mathrm{~cm}$ x $40 \mathrm{~cm}$ x $60 \mathrm{~cm}$ dan diberi pakan berupa cairan madu $10 \%$ yang diserapkan pada gumpalan kapas. Di dalam kurungan diletakkan 3-5 helai daun brokoli sepatu sebagai tempat imago meletakkan telur. Tangkai daun brokoli tersebut dimasukkan ke dalam wadah film yang berisi air, agar turgor dapat dipertahankan (tidak mudah layu). Kelompok telur yang terdapat pada daun tersebut dikumpulkan setiap hari dan ditempatkan dalam cawan petri berdiameter $15 \mathrm{~cm}$. Menjelang menetas, kelompok telur dipindahkan ke dalam wadah plastik berukuran $28 \mathrm{~cm}$ x $20 \mathrm{~cm}$ x $5 \mathrm{~cm}$ yang dilengkapi dengan jendela kasa. Larva yang baru menetas (instar I) diberi pakan daun brokoli bebas pestisida. Larva yang baru memasuki stadia instar II digunakan sebagai serangga uji.

Penelitian disusun secara faktorial 6 × 3 mengikuti rancangan acak lengkap dengan 3 ulangan. Faktor pertama adalah lama penyimpanan ekstrak yang terdiri dari enam taraf, yaitu 0 minggu $\left(S_{0}\right) ; 1$ minggu $\left(S_{1}\right) ; 2$ minggu $\left(S_{2}\right) ; 3$ minggu $\left(S_{3}\right) ; 4$ minggu $\left(S_{4}\right)$, dan 5 minggu $\left(S_{5}\right)$. Faktor kedua adalah Konsentrasi aplikasi yang terdiri dari tiga taraf, yaitu $10 \%\left(\mathrm{~K}_{1}\right) ; 15 \%\left(\mathrm{~K}_{2}\right)$; dan 20\% $\left(\mathrm{K}_{3}\right)$. Dengan demikian terdapat 18 kombinasi perlakuan yang akan diuji.

Data hasil penelitian diolah dengan sidik ragam menggunakan uji Fisher (SAS Institute, 1990). Nilai tengah perlakuan dibandingkan dengan uji jarak berganda Duncan $\alpha=0,05$.

\section{Pelaksanaan Penelitian}

a. Ekstraksi

Bahan baku berupa biji mahoni yang telah dikupas dihaluskan dan dikeringanginkan dengan penggiling biji (Grader). Serbuk yang diperoleh ditimbang sebanyak $250 \mathrm{~g}$, lalu bahan tersebut dimasukkan ke dalam ember plastik. Molase sebanyak 50 cc disiapkan kemudian diencerkan menjadi $250 \mathrm{cc}$. Bioaktivator (EM4) disiapkan sebanyak $50 \mathrm{cc}$ kemudian ditambahkan pada molase yang telah diencerkan pada kegiatan sebelumnya. Molase encer yang mengandung bioaktivator dituangkan ke dalam ember yang telah terisi bahan baku. Menambahkan air sebanyak 11 ke dalam ember kemudian ditutup rapat. Bahan baku yang telah diberi biaktivator disimpan selama 4-7 hari agar terjadi proses fermentasi (selama fermentasi tidak boleh terkena sinar matahari langsung, gas dibuang dengan membuka tutup ember secara perlahan-lahan). Hasil fermentasi disaring, ampasnya dibuang, dan cairannya sudah dapat digunakan sebagai insektisida. Insektisida yang dihasilkan disimpan sesuai dengan perlakuan yang direncanakan (yaitu 0,1, 2, 3, 4, dan 5 minggu). 
b. Pengujian

Ekstrak biji mahoni hasil fermentasi diuji dengan metode pencelupan daun seperti yang diuraikan oleh Prijono (1999). Potongan daun bayam dicelupkan ke dalam ekstrak yang telah disimpan sesuai perlakuan sampai basah merata kemudian dikeringudarakan. Setelah kering, dua lembar daun bayam dimasukkan ke dalam gelas pelastk (diameter $9 \mathrm{~cm}$ ) yang dialasi kertas tisu, kemudian 7 ekor larva ulatgrayak instar II dimasukkan ke dalamnya. Lama pemberian pakan beperlakuan adalah 48 jam.

Pengamatan ditujukan pada jumlah larva yang mati (mortalitas) setelah 48 jam memakan daun berperlakuan.

\section{HASIL DAN PEMBAHASAN}

Ekstrak biji mahoni hasil fermentasi yang diujikan dalam penelitian ini ternyata memiliki aktivitas insektisida terhadap larva ulatgrayak. Berdasarkan sidik ragam (uji Fisher) terhadap data mortalitas larva ulatgrayak setelah diberi pakan yang mengandung ekstrak biji mahoni sesuai perlakuan dalam penelitian ini, tampaknya tidak ada interaksi antara lama penyimpanan ekstrak dengan konsentrasi pemberian. Dengan demikian dapat dikatakan bahwa faktor lama penyimpanan dan faktor konsentrasi berpengaruh saling bebas terhadap mortalitas ulatgrayak. Dengan kata lain pengaruh faktor lama penyimpanan konsisten pada setiap taraf faktor konsentrasi, sebaliknya pengaruh faktor konsentrasi juga konsisten pada setiap taraf faktor lama penyimpanan. Oleh karena itu perlu diperbandingkan nilai tengah masing-masing faktor. Perbandingan nilai tengah pengaruh lama penyimpanan ekstrak terhadap mortalitas ulatgrayak disajikan pada Tabel 1, sementara perbandingan nilai tengah pengaruh konsentrasi ekstrak terhadap mortalitas ulatgrayak disajikan pada Tabel 2 .

Tabel 1. Uji nilai tengah pengaruh lama penyimpanan ekstrak terhadap mortalitas ulatgrayak

\begin{tabular}{cc}
\hline Lama penyimpanan ekstrak (minggu) & Mortalitas $(\%)$ \\
\hline 0 & $100.00 \mathrm{a}$ \\
1 & $100.00 \mathrm{a}$ \\
2 & $100.00 \mathrm{a}$ \\
3 & $61.90 \mathrm{~b}$ \\
4 & $34.92 \mathrm{c}$ \\
5 & $0.00 \mathrm{~d}$ \\
\hline
\end{tabular}

Keterangan: data mortalitas larva dianalisis setelah ditransformasi $\sqrt{X+0,5}$, angka-angka yang diikuti oleh huruf yang sama menunnjukkan tidak berbeda nyata berdasarkan uji jarak berganda Duncan $(\alpha=5 \%)$ 
Pada Tabel 1 terlihat adanya perbedaan mortalitas larva ulatgrayak setelah diberi pakan yang mengandung ekstrak biji mahoni hasil fermentasi yang telah disimpan antara 0 sampai 5 minggu. Penyimpanan selama 0 sampai 2 minggu menyebabkan mortalitas larva ulatgrayak tertinggi yaitu $100 \%$ dan tidak berbeda nyata antara sesamanya, namun berbeda sangat nyata terhadap mortalitas larva ulatgrayak setelah diberi pakan yang mengandung ekstrak biji mahoni yang telah disimpan selama 3 sampai 5 minggu. Fakta ini menunjukkan bahwa penyimpanan ekstrak biji mahoni hasil fermentasi dapat menyebabkan penurunan keefektifannya. Hal ini sesuai dengan pernyataan Prijono (1999) bahwa insektisida nabati yang disimpan dan terdedah di lapangan sangat mudah terdegradasi sehingga keefektifannya menurun.

Tabel 2. Uji nilai tengah pengaruh konsentrasi ekstrak terhadap mortalitas ulatgrayak

\begin{tabular}{cc}
\hline Konsentrasi (\%) & Mortalitas (\%) \\
\hline 20 & $74.60 \mathrm{a}$ \\
15 & $63.49 \mathrm{~b}$ \\
10 & $60.32 \mathrm{c}$ \\
\hline
\end{tabular}

Keterangan: data mortalitas larva dianalisis setelah ditransformasi $\sqrt{X+0,5}$, angka-angka yang diikuti oleh huruf yang sama menunnjukkan tidak berbeda nyata berdasarkan uji jarak berganda Duncan $(\alpha=5 \%)$

Ekstrak biji mahoni hasil fermentasi yang telah disimpan selama 3 minggu juga mengalami penurunan efektivitasnya, namun masih cukup efektif karena masih mampu menyebabkan mortalitas serangga sasaran sebesar $61,90 \%$. Dengan demikian ekstrak biji mahoni hasil fermentasi hendaknya disimpan tidak melebihi 3 minggu.

Faktor konsentrasi ekstrak biji mahoni hasil fermentasi yang diujikan juga menimbulkan mortalitas larva yang berbeda (Tabel 2). Mortalitas tertinggi yaitu $74.60 \%$, terjadi pada sekelompok larva yang diberi pakan yang mengandung ekstrak biji mahoni dengan konsentrasi 20\%. Mortalitas akibat perlakuan ini berbeda nyata terhadap mortalitas larva yang terjadi akibat perlakuan konsentrasi $15 \%$ dan $10 \%$, secara berurutan yaitu dapat menyebabkan mortalitas larva ulatgrayak sebanyak $63,49 \%$ dan $60.32 \%$.

Secara statistik telah teruji bahwa perlakuan konsentrasi $20 \%$ adalah yang terbaik, namun apabila ketersediaan ekstrak sangat terbatas, aplikasi dengan konsentrasi 10\% masih cukup efektif karena dapat menyebabkan mortalitas larva ulatgrayak lebih dari $60 \%$. Penurunan populasi serangga hama sebesar 60\% mampu menurunkan tingkat luka ekonomi (Economic injury level) sehingga populasi hama yang masih bertahan hidup tidak menimbulkan kerusakan secara ekonomis. 


\section{KESIMPULAN}

Berdasarkan hasil percobaan ini dapat disimpulkan bahwa ekstrak biji mahoni yang diperoleh dengan cara fermentasi memiliki aktivitas insektisida terhadap larva ulatgrayak. Keefektivan ekstrak biji mahoni yang diperoleh dengan cara fermentasi terhadap larva ulatgrayak dipengaruhi oleh lama penyimpanan dan konsentrasi aplikasi. Kedua faktor tersebut berpengaruh saling bebas terhadap mortalitas ulatgrayak. Aktivitas insektisida ekstrak biji mahoni yang diperoleh dengan cara fermentasi dapat disimpan sampai tiga minggu. Ekstrak yang disimpan lebih dari tiga minggu aktivitas insektisidanya sangat rendah bahkan hilang. Ekstrak biji mahoni hasil fermentasi sangat efektif mengendalikan populasi larva ulatgrayak pada konsentrasi $20 \%$ dan cukup efektif pada konsentrasi $10 \%-15 \%$.

\section{DAFTAR PUSTAKA}

Chiu, S. F. (1985). Recent research finding on Meliaceae and other promising botanical insecticides in China. Z Pflkrankh Pflsch, 92, 310-319.

Dadang. (1999). Sumber Insektisida Nabati. Dalam Nugroho, B.W., Dadang, \& Prijono, D (Eds.), Bahan Pelatihan Pengembangan dan Pemanfaatan Insektisida Nabati (pp. 8-20). Bogor: Pusat Kajian Pengendalian Hama Terpadu.

Ewete, F., Nicol, R.W., Hengsawad, V., Sukumalanand, P., Satasook, C., Wiriyachitra, P., Isman, M.B., Kahn, Y., Duval, F., Bir Philogene, \& Arnason, J.T. (1996). Insecticidal activity of Aglaia odorata extract and the active principle, rocaglamide, to the European corn borer, Ostrinia nubilalis Hubn. (Lepidoptera: Pyralidae). J. Appl. Entomol., 120, 483-488.

Hamdani, Supriyatdi, D., \& Yasir, A. 2004. Metode pembuatan dan efektivitas ekstrak biji mahoni dan biji mahoni (Swietenia mahagoni L.) terhadap ulatgrayak (Spodoptera litura F. (Lepidoptera: Noctuidae). Jurnal Penelitian Pertanian Terapan, 6, 118-124.

Hamdani \& Supriyatdi, D. (2005). Efektivitas insektisida ekstrak biji mahoni terhadap hama penghisap buah lada (Dasynus piperis China) (Hemiptera; Coreidae) (Laporan Penelitian). Bandar Lampung: Politeknik Negeri Lampung.

Kalshoven, L.G.E. (1981). The Pests of Crops in Indonesia. Revised and Translated by Van Der Laan, P.A. Jakarta: PT Ichtiar Baru - Van Hoeve.

Koul, O., Shankar, J.S., Metha, N., Taneja, S.C., Tripathi, A.K., \& Dhar, K.L. (1997). Bioefficacy of crude extracts of Aglaia species (Meliaceae) and some active fractions against lepidopteran larvae. J. Appl. Entomol., 121, 245-248.

Kusmayadi, A. (1999). Program Nasional Pengendalian Hama Terpadu. Jakarta: Direktorat Bina Perlindungan Tanaman Departemen Pertanian.

Prijono, D. (1998). Insecticidal activity of meliaceous seed extarcts against Crocidolomia binotalis Zeller (Lepidoptera: Pyralidae). Bul. Hama dan Penyakit Tumbuhan, 10, 1-7. 
Prijono, D. (1999). Prospek dan strategi pemanfaatan insektisida nabati dalam PHT. Dalam Nugroho, B.W., Dadang, \& Prijono, D (Eds.), Bahan Pelatihan Pengembangan dan Pemanfaatan Insektisida Nabati (pp. 1-7). Bogor: Pusat Kajian Pengendalian Hama Terpadu.

Pusat Pelatihan Pertanian Terpadu dan Akrab Lingkungan. (2005). Sistem Pertanian Terpadu, Berkelanjutan, dan Ramah Lingkungan. (Materi Pelatihan Pertanian Organik). Bogor: Jawa Barat.

SAS Institute. (1990). SAS User's Guide Version 6. North Carolina: SAS Institute. 